\title{
ADVANCED METALLIC SEAL FOR HIGH TEMPERATURE APPLICATIONS
}

\author{
Terence Nolan, Jeff Swensen, and Jeff Layer \\ EG\&G Pressure Science \\ Beltsville, Maryland
}

\begin{abstract}
The U.Plex(1) was designed to allow greater elastic deflection capability in a given gland volume than the now conventional E-sealø. Greatior deflection capability with the associated lower bending stresses provides several benefits. For pneumatic duct joints, the axisl free height is increased to allow sealing of flanges with weld distortions signifieantly in excess of what could be colerated with E-scals(6). This performance is achieved while maintaining the reusability and ease of assembly typical of E-sealio rigid duct jornts. For turbine engine air seal applications, which are yuite often at temperatures where stress relaxation of metallic seals needs to be considered and significun axial cavity excursions exist, the lower stresses inherent in the U-Plext design can provide exiended seal performance, life and applicability with current. suitable materials. The development of a betrer "duct joint seal" led to defining seal characteristics which needed to be improved. These characteristics include increased elastic dellection. coniormity to local deformations, improved pressure energization characteristics. lower force to compress (while maintaining the same level of sealing capability) and betrer geometric stability. These features assuciated with the U-Plex(1) design, result in both performance benefits for the seal and manufacturing benefits associated with producing the cavily for the seal to operate in.
\end{abstract}

\section{Descrivion}

The geometry of the U.Plex(9) seal differs from the Escalfe in that the "leys" of the seal are incorporated in the convolution of the seal where an E-sealis has a distinct convolution and "legs". This permits the convolution ratius to be significantly larger. The basic U-Plex consisis of two plies of material. The plies of material are not circumferentially welded. The end of the U-Plex(legs sure tightly curled backward to provide a good scaling land arca and to shield the interstitial gap between the plies from the higher pressure medium to be sealed, by facing the gaps towards the lower pressure side.

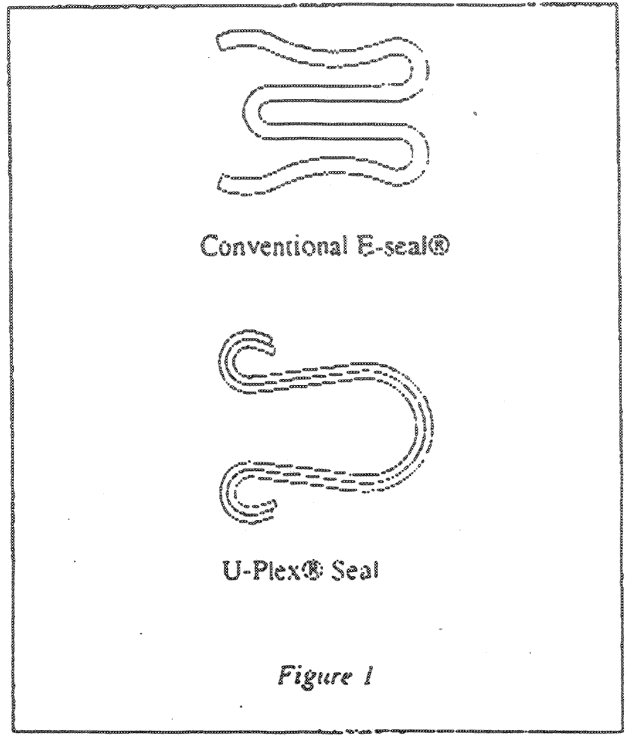

The U.Plex(1) design can be adjusted in accommodate different applications by varying the number of plies, ply thickness, ply matcrial, number of convolutions, seal dimensions, and adding wear resistant coatings. Note that the individual plies could be mate from different type or thickness material.

A multiple ply seal, provided all phes experience the pressure loading. allows pressure induced stresses to he evenly split between the plies. In a imo ply seal, at a given pressure, the hending stresses crtalcd by deflection would be one half that of a single ply seal of the same total thickness. thus uncreasing the elastic deflection capability, which is key to maintaining scaling contact with the cavily surfaces.

Another aspect of the U-Plexw seal design that reduces sperating stresses is the large convolution radius. The seal is designed so that compression of the seal oniy takes place on the seal "legs". maximizing the deflectable length of the seal. The large ratius can then provide a brised area over which the bending strain is 
distributed and allows pressurization to induce forces that oppose this strain. resulting in a much lower combined suress siruation. This effect serves to minimize stress relaxarion, which could compromise seal performance, at during the majority of time the seal is at operating temperature, it is also pressurized. E-seals also benelit from pressurization, however, the effect is much less prenounced due to the tighter bend radii. Figure 2 is a comparison of the stress contours of the two cross sections.

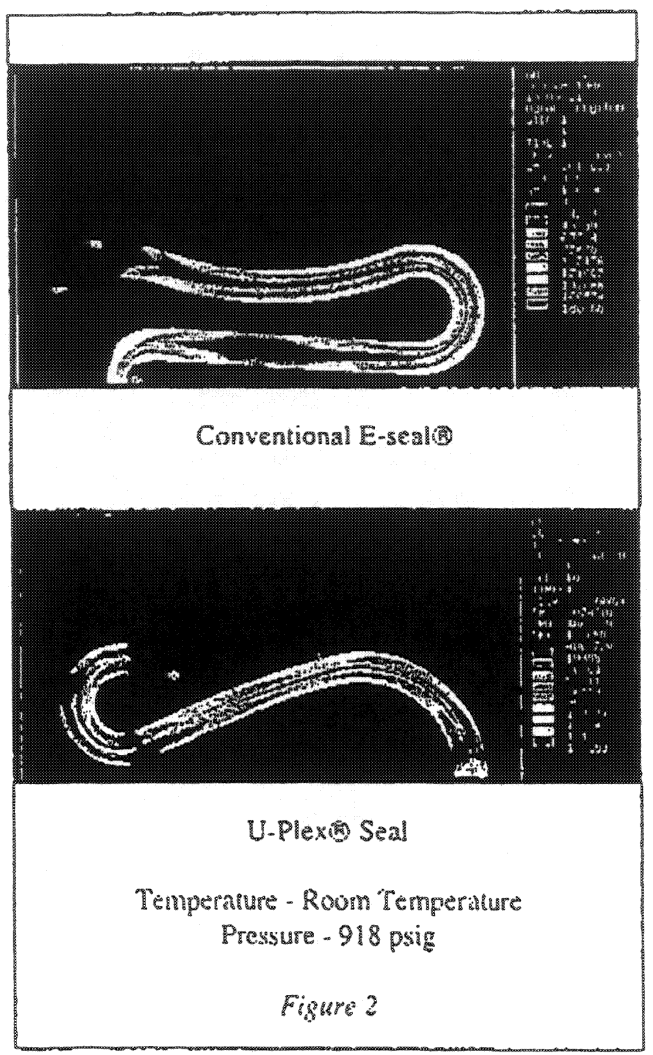

In some applications, buckling of flexibic metallic seals can be a concern due to the relatively low thermal inertid of the seal or transient differential movements. The geometry of the U.Plexe seal pesists buckling better than the conventional E-seats since the large radius and reversed curled legs result in a higher momen of inertia in the critical plane. The reverse curl on the seal legs provides an additional benefit in segmenicd cavily applications; llow induced resonance has been suspeciced of causing occusional high cycle fatigue failures of seals, the curled le grs grealy increase the resonan freguency of the seal, thus preventing a "reed" effect. Recent testing has confrrmed that the U. Plex@ design minimizes seal resonance.

\section{Pneurratic Duce Joint Applications}

The U-Plex( Seal improves the integrity and robustncss of Rigid Ducting Joints. Figure 3 illustrates a typical rigid ducting joint with a U.Plexititinstalled. All EG\&G Pressure Science rigid duct joint seals, both E-scals(3) and U-Plex(e) seals, are heat treated Inconel 718.

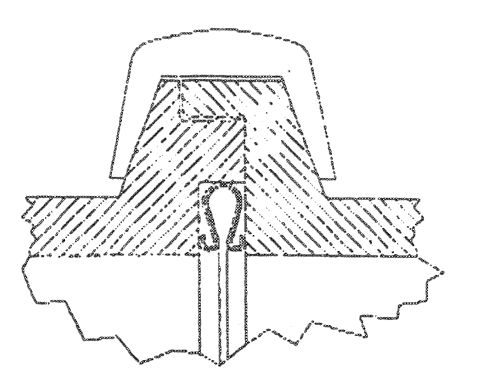

Figure 3

Tesing has been performed to compare the leakage control capability between the U.Plexis seal and the conventional E-seal(s) in both ideal and out-of-nat conditions. The increased elastic deflection capability of the U-Plex(B) Seal will allow it to seal when assembled in weld distorted langes which are as much as 2.5 to 5 times worse than those in which the convention E-seal(e can accommodate. This allows relaxed flange flatness tolerance requirenents and reduces retvork of the ducting joint flanges. Figure 4 is a comparison of the conventional E-seilo to the U. Plex(A) as they relate to axial flange cavity height as specified by Aerospace Standard. SAE Document, AS 1895.

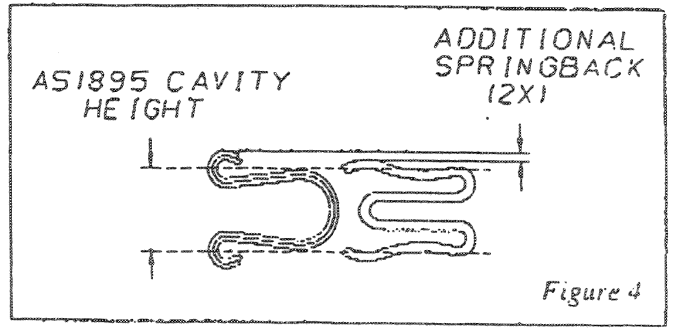


It is important to note that the U-Plcxis seal, by design, stores significantly more strain energy to accommodate flange distortions and deflections. Therefore, the highly compliant U-Plex(9) seal can accommodate relatively large local deformations. For example. duct joints from $\varnothing 1.50^{\prime \prime}$ to $\varnothing 3.50^{\prime \prime}$ assembled with the UPlex@ seal will adequately seal flanges that are up to .011" per linear inch circumference out-of-flat. This value increases to .018" per linear inch circumference out-of-flat for diameters greater than $3.5^{\circ}$

The U-Plex(B) Seal is qualified to the Aerospace Specification for Rigid Pneumatic Joints AS1895. under section AS1895/23. A $07.5 "$ U-Plex® Scal was endurance tested in a Standard Profile Rigid Duct Joint for 200.000 cycles. Each cycle consisted of pressurizing the duct and applying a bending moment to the duct while at $1200^{\circ} \mathrm{F}$. The leakage from the joint remained consistently low throughout the test.

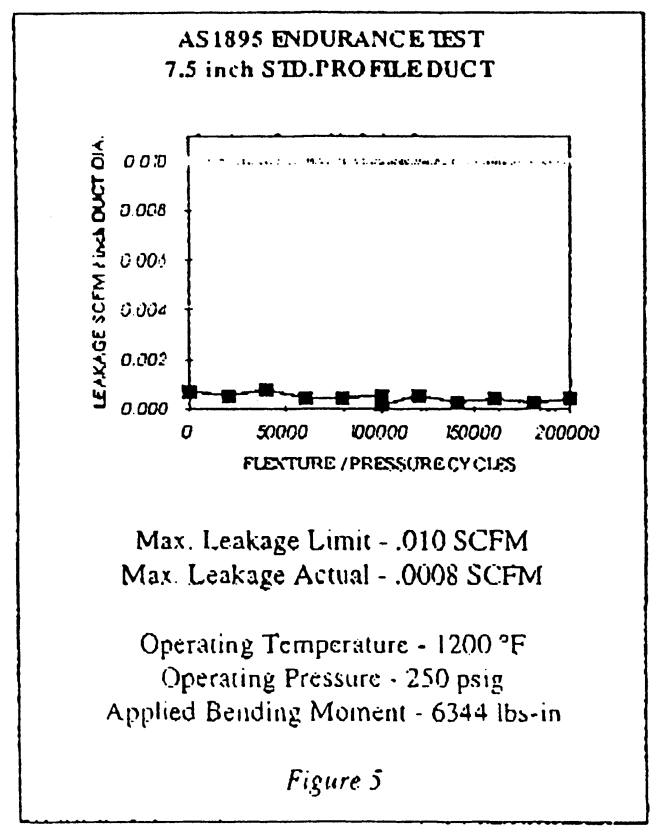

Additionally, the L-Plexill Seal was able to pass the difficult AS1895 Safety Latch Test. This test historically has been a test that the rigid joint utilizing a convenciunal-E-scal@, or similar sealing method, has not been able to męet in all sizes with regard to the specified leakage limit. The test involves taking a pressure loaded rigid joint and intentionally causing a bolt failure. The intent of the test is to insure that the joint docs not separate as a result of an unlikely bolt failure. The safety latch is required to keep the joint intact while a finite excessive leakage requirement is met. The conventional E-seal(B). or simular sealing method, can not meet the speciticd leakage and is not functional subsequent to the test. The U-Plex (1) Seal meets the required leakage of the AS1895 Safety Latch Test and is still functional subsequent to a successful test. The ability of the U.Plex(i) Seal to meet this demanding requirement is due (1) it's improved pressure energization characteristics, and lower resistince 10 bending. Figure 6 is a graph of leakige vs. axial cavity height. The E-seal由 is not capable of sealing at cavity heights greater than the scal's axial free height. The U. Plex\$ seal is capable of sealing at cavity heights greater than it's axial free height.

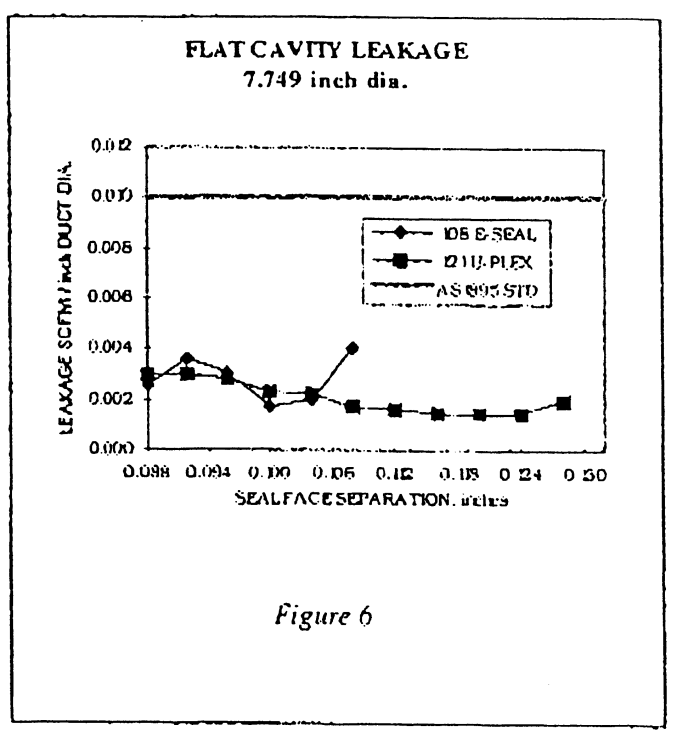

The U.Plex: Seal can achieve the leakage control capabilitics of the conventional E-sealta. ar significantly lower contact loads. The E-sealio. qualitied 10 ASI\$95, has a force-to-compress of approximalcly 60 los per circumferential inch, whic the U-Plex(S) Seal, qualified to AS1895, has a force-10-compress of approximately 20 lbs per circumferential inch. Thes fealure will allow the same level of sealing with iess wear of the sealing surfacis. This was evident by examination of the hange scaling surfaces after the 200,000 cycle endurance test. Thus beneril is mote applicable in the curbine eng!ne applications ivisere wear is a more significant issue. 


\section{Turbine Engine Air Seal Applications}

Many of the features and benetits of the U-Plexß Seal identified for pneumatic rigid joint applications can be applied to turbine engine air seal applications. These features are:

- Increased elastic deflection

- Confomuty to local deformations

- Improved pressure energization characteristics

- Lower force to compress

- Lower wear

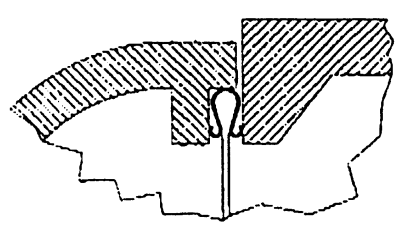

Figure 7 - Typical Turbine Engine' Air Seal Application

Increased elastic deflection and a lower spring rate allows a larger deflection range over which the internal suresses within the cross section of the seal can remain below the elastic limit of the scal material. Since the cyclic stresses in the scals are primarily a function of axial deflection, not axially applied loads, the lower spring rate will provide a better stress profile for low cycle fatigue

Improved pressure energization characteristics will allow belter conformity in applications where the axial cavity increases during operation and in applications where stress relaxation is a concern. With any "spring loaded" lace scal, the contact load will decrease as the axial cavity height increases. Since the U-Plex(1) Seal has better pressure energization characteristics. as demonstrated in the AS1895 Safecy Latch Test, the contiat load will be higher for the U-Plex(B). compared (1) a conventional E-seal(B) as the axial cavity increases. and all other pirameters are equal. The betice pressure energization characteristics will reduce the effects of surcss relaxatuon at high temperatures. In typical Eseall(k) applications where stress relaxation is an issue, the seal axial tree height will appronch the axial cavity height dimension during operation, thus reducing the contact load and level of sealing. This phenomena will also occur with U-plex(B) Seal design, but the effects will be minimized by the pressure opposing the deflection induced strain and the fact that the better pressure energization of the scal will result in sufficient contact load as long as the seal system is designed such that line-to-line contact is maintain. For example, in the AS1895 Safety Latch Test, the axial eavity height after bolt failure is greater than the axial free height of the seal and a certain level of sealing ability is maintained.

The lower force to compress inherent to the U-PlexiB design will provide better wear characteristics, while maintaining the same level of sealing. Additionally and more importantly, the U.Plcx(B) design cian accommodate more than one material type. Hence, a hybrid U.Plex(B) could be made from two materials, the material making up the seal contact surface would be chosen based on optimizing the tribological pairing between seal and cavity: and the other material would be chosen on material strength propertics. The U. Plex (4) can be manufactured in any of the high temperature alioys that $E$-seals(i) are currently produced in. These materials are as follows:

- Inconel 715

- Waspaloy

- Haynes 214, 188. 242

- Rene 41

- Incoloy 909

- and new alloys as they become available

Additionally, these seals can be cuilted with a Tribaloy coating to provide wear resistance for the seal. The operating temperalure and pressure limits for both the E-seal(t) and the U.Plex(8) are dependent on the material selection and application parameters.

To datc limited testing has been done on layege diameter $\left(=\varnothing 20^{\circ}\right)$ U-Plex(B) Seals. The U-Plex(e) scal will be tcsted in a test rig which call simulate opcrialung temperature, pressure and differential radial movements berween the seal and arity wall. This test will also provide insight as to if the curled leg improves resistance to high cycle latiguc. One large diameter (j. Plex(8) has been tested in this rig. This seal was split radially in one location. Large diameter E-seals'sis are radially split in some high prissure turhıne applications to minimize the effects of musmaccied thermal and/or radial restraints of the seal cavicy The splic in the seal allow's circumferential growth, instead of ridiai growth. of the seat and therefore removes the decrimental hoop loctds that could induce buckling of 
the seal. During previous testing of convention E. seals $(\mathbb{B})$ in this test rig, audible high pitched noise was observed. It was hypothesized that the noise was treing created by high pressure air escaping through the cavity segments over an unsupported section of the seal acting to produce a "reed" effect. In the same test set-up, the U-plex() Seal did not exhibit the same noise behavior. It is theorized that the curled legs greatly increase the resonant frequency of the seal, preventing a "reed" effect.

\section{Further Tescins and Dezveloomens}

For small diameler U-Plex Seals, less than $\varnothing 7.5^{\circ}$ and primarily for pneumatic duct joint applications, all testing is complete for qualification to AS1895/23 and tests to verify performance improvement over the conventional E-seal( is) is complete. Additionally, all manufacturing process developinent is complete.

Testing and development of the larger diameter UPlex(B) seals, for turbine engine applications, will continue. A large diameter, $=\varnothing 30 "$ ", U-Plex(H) seal will be tested in a test rig which can simulate operating temperiture, pressure and differential radial muvements between the seal and cavity wall. The lesting is inlended to compare/evaluate the perfornance benefits of the U.Plexit Seal identified above to the current performance of the E-seal(s).

\section{Conclusion}

Durng the design process of a typical E-sealia application. wherc a new seal section is required, the seal cross section is usually optimized for maximum elastic deflection, lower compression loads and sufficient geometric stability. The U-Plex(x) Seal is, in fact, a truly optimized metallic seal cross section with additional features, such as, improved conformity to local deformation and improved prossure energization characteristics. Although first developed to "raise the bar" on performance for pneumatic duct joint seals, it is quite evident that the benefits associared with this new metallic seal cross section can be exended to improve large metallic seal cechnolugy. The U-PlexiB dosign is a next generation product. reflecting 30 years of experience in resilient metallic seals. 